\title{
The Disruptive Effects of COVID-19 on the Aviation Industry, Food Industry, and E-commerce Industry
}

\author{
Cheng Dai
}

\author{
College of Liberal arts and sciences, University of Illinois at Urbana-Champaign, Champaign, IL, 61820, US \\ Corresponding author's e-mail: Vivian.wang@cas-harbour.org
}

\begin{abstract}
This article mainly focuses on the disruptive effects of COVID-19 on the world's aviation, food, and e-commerce industry, discussing the background information of COVID-19, how the COVID-19 disease is affecting these industries, and suggestion about what local governments and companies should do during the outbreak. Using statistical data and perspectives from other articles and professional websites, this article analyzes the impact of COVID-19 on these three industries, and concludes that COVID-19 has caused serious harm to the aviation and food industries, but has brought great benefits and challenges to the e-commerce industry.
\end{abstract}

Keywords: COVID-19, world's economy, aviation industry, e-commerce, food industry

\section{INTRODUCTION}

Coronavirus disease 2019, or COVID-19, is an infectious disease. It was first detected December 2019 in Wuhan, China, and since then the virus has spread globally, affecting over 188 countries in the world. According to CDC [2], as of July 2020, there are more than 11.4 million cases detected in the world, causing over 535,000 deaths, and 2,886,267 cases are reported in the United States with total deaths of 129,811 . For the past few months, many countries are forcing lockdown policy, but lockdown also causes economic problems since demand and supply are both decreasing. The analysis part of this article will specifically analyze how COVID-19 affects the aviation, food, and e-commerce industry. The next suggestion will give suggestions to the local governments and companies of these three industries. The final conclusion part will present a brief conclusion of this article.

China's economic response to the first outbreak of COVID-19 is the motivation for this article. Back in December 2019, when the coronavirus first started to spread in Wuhan, people did not expect this virus to seriously damage the world's economy. Later in January, the coronavirus spread so quick in China that the government had to implement national quarantine to slow the spread of the virus. As it is known that China makes up a third of manufacturing globally, exporting the largest quantity of goods in the world. China also has a large market due to its huge population, so people started to realize this would hurt the world's economy seriously in the future. But the fact is even more pessimistic, the virus began to spread globally, and the world's economy was damaged not just because of the international trades with China but domestic production and consumption as well. Therefore, this article will analyze the influences of
COVID-19 on the aviation industry, food industry, and E-commerce industry.

\section{ANALYSIS}

The aviation industry presents an U-shaped trend based on the change of weekly flight frequency from February to July. Both of the passenger and cargo aviation are suffering from the coronavirus pandemic, but clearly the situation of passenger aviation is much worse: passenger aviation will lose about 314 billion dollars in 2020 [3]. According to Statista [3], from January 5 to June 29, the weekly flight frequency in the U.S. dropped by approximately 57.4 percent, with a global drop of 56 percent, but this is not the worst case. By May 4, the change of weekly flight frequency in the U.S. reaches the lowest point of -74.5 percent, which is far worse than on June 29 [3]. Starting from February 2020, there is an increasing number of countries decide to restrict international and domestic travel due to the coronavirus. For instance, the United States government prohibits foreign nationals who have been in China, Iran, European Schengen area, United Kingdom, Republic of Ireland, and Brazil from entering the United States according to CDC [2]. Travel restriction left airlines with no choice but cancelling most of the flights. Also, the virus significantly decreases the demand of travel since most of the people are not willing to travel during the pandemic, bringing a huge damage to the entire travel and tourism industry. Specifically, the global revenue of the travel and tourism industry is expected a 34.7 percent decrease this year [3]. Revenue reduction forces airline companies to lay off employees, and many airlines are now facing the problem of bankruptcy. Fortunately, aviation industry is recovering starting from May 4, but with a low rate, because travel 
restriction or travel ban still exists.

The coronavirus affects the aviation industry and the food industry. The food industry is affected mainly due to the lack of workforce, raw material problem, and unstable demand. Similar to the situation of aviation industry, numerous companies in the food industry are forced to lay off employees to make up for lost revenue. Besides, because of the national quarantine, many workers cannot go to work. Also, the supply and transportation of raw material becomes a problem. Usually the raw materials of the food industry come from all over the world. However, due to the epidemic, the supply is in deadly for food manufacturers [1]. Australian food manufacturers are good examples. Australia imports a large quantity of crop protection products and agrochemicals from China, but China's crop protection products manufacture is affected by the coronavirus, and the virus also causes logistics and traffic restrictions problem. Accordingly, many Australian food manufacturers are now suffering from supply disruptions, forcing them to find alternative suppliers [6]. The third problem is the unstable demand. Lots of food retail stores and foodservice outlets are more likely to face this kind of problem [6]. For one thing, people are required to stay at home, thus most of the food retail stores and restaurants will have less customers than before the epidemic. For another, according to Acheson [1], COVID-19 can survive on the food surface for two days, so it is possible for people to get infected, if the food producing process involves infected individuals and unhygienic practices. As a result, even though many stores and restaurants provide online takeout service, they will still lose a huge number of customers.

People take it for granted that e-commerce sales will grow after the outbreak of coronavirus. In fact, not all e-commerce sellers benefit from the spread of the coronavirus. On the one hand, the online shopping demand has increased dramatically because people are trying to avoid retail stores during the pandemic, and many e-commerce stores are receiving benefits from the pandemic. Global shopping activity continuously to grow, and as of April 2020, the global order count increased by 96 percent compared with April 2019 [4]. Although shopping activity slightly declined in May, the overall trend is still upward sloping. JD.com is a good example of e-commerce companies that gain benefits from the pandemic. According to Kulach [5], JD's sales of fresh food increased 215 percent within 10 days by Feb 2 . Amazon's stock price keeps increasing, and it is already 28 percent higher this year by April 16 [9]. Amazon hired more than 100,000 new employees since the outbreak because of the surge in demand [9]. On the other hand, the lack of workforce interrupts manufacture or the supply chain because of epidemic as mentioned before. In addition, the sharp increase of online shopping brings challenges to the whole supply chain. Shortages will eventually increase prices, giving extra burden to consumers. According to Mathradas [7] the supply chains of approximately 75 percent of all U.S. companies are affected during the outbreak, resulting in shortages, order cancelling, and customers' unsatisfaction. The outbreak also interrupts shipping, which is an important part of e-commerce. Many companies, UPS and FedEx for example, are experiencing labor shortage and an increase of shipping demand, so they have to extend delivery dates for most of the orders [7]. Overall, what COVID-19 brings to the e-commerce industry is double-sided, companies are receiving both unprecedented benefits and challenges.

\section{SUGGESTION}

Countries around the world are taking different actions now to reopen the country in numerous ways. For instance, all 50 states of the U.S. begin to reopen or make plans for reopening, even though confirmed cases are still growing [10]. The fact is that the outbreak can become serious again as people go back to work and return to their normal social life. For example, Texas decided to close bars after a surge in confirmed cases [10]. Therefore, the government should balance the risk of more virus infections with the benefits of saving the economy, and postpone the resumption of work because reopening is risky, even though the peak of COVID-19 infection is gone according to CDC's model, it is possible for the outbreak to reach its peak again if people all go back to school and work, which will cost more to recover in the future. In addition, epidemic subsidies are necessary to help those who suffer financial hardship during the epidemic. Numerous people are suffering from financial problems during the outbreak because they have no source of income. This can cause mental health problems and social unrest, which will damage the stability of society. Thus, it is important to give enough financial support to those who need help.

The aviation industry experiences difficulties during the outbreak, and it is hard to recover in a short time because of the travel restrictions. Although all airlines have suffered great losses during this period, they are still responsible for the health and safety of their passengers. Airlines should reduce flights to highly affected areas and ensure that passengers take appropriate precautions. United Airline recently decides to add about 25,000 flights and give up blocking middle seats [8]. The decision means to make up for lost revenue during the outbreak but the possibility of getting more infections will increase. Qatar Airways provides a good example of what airlines should do during the outbreak. According to Mulfati [8], passengers are requested to use face shields in flight, and Qatar Airways provide face mask, gloves and hand sanitizer for passengers on board. It is true that airlines have struggled to survive the outbreak, but passengers' heath also matters.

The pandemic coronavirus negatively affects the global food industry. For food manufacturers, it is important to find alternative and stable raw material suppliers if the original suppliers are from affected areas. For restaurants and other food retail stores, workers should check their daily body temperature before working, and handle and deliver food carefully, making sure customers will not get infected from the food. This can be done by requiring staff to use masks and gloves when handling and delivering 
food, regularly disinfecting working areas, and many other methods. Another suggestion for restaurants affected by COVID-19 is that restaurants can work together to sell food together. Chowbus, a take-away application, provides a great example to restaurants and beverage stores. For instance, $\mathrm{A}$ is a Chinese restaurant and $\mathrm{B}$ is a beverage store, many customers love the food of restaurant A but also want a great cup of milk tea from beverage store B, and they can order the food and milk tea together but Chowbus only charges one delivery fee. A and B both provides discount if customers choose to order both the food and beverage, bringing more online order to both the restaurant and beverage store.

The e-commerce industry is facing both positive and negative outcomes brought by the pandemic. The most important thing for e-commerce companies during the outbreak is to deal with the challenges. Because it is hard to control the supply chain as sellers, what sellers can do is to: present real-time stock or inventory information to the customer, make sure to tell customers when to expect out-of-stock products back in stock, and update daily tracking information to the customer.

\section{CONCLUSION}

This article focused mainly on the impacts of COVID-19 on the world's aviation industry, food industry, and e-commerce industry. There are numerous other industries that are affected as well during the outbreak, but this article is not able to cover them all. Also, the suggestion part of this article is not objective and specific enough. For example, the balance between increasing infection and saving the economy involves several aspects, and obviously the article does not take them all into account, because the overall attitude of the suggestion section is more toward the side of health. The future situation can still not be predicted because of the uncertainties of COVID-19, so it is not for sure when the epidemic will end. However, it is clear that most of the online businesses are benefiting from the pandemic while other businesses are not, and there are a lot of traditional businesses choose to transfer online for the purpose of surviving. Thus, the key for companies to survive during this time is to adapt and make changes. Finally, thanks for the data provided by CDC and Statista, as well as the academic advice from professor Xian Sun and support from outside sources.

\section{ACKNOWLEDGMENT}

I want to say thank you to all the people who helped me with the writing of this paper.

\section{REFERENCES}

[1] D, Acheson. Food Industry Coronavirus Impact. 2020. [online] Quality Assurance \& Food Safety. Available at:

<https://www.qualityassurancemag.com/article/food-in dustry-coronavirus-impact/>.

[2] Centers for Disease Control and Prevention. Coronavirus Disease 2019 (COVID-19). 2020. [online] Available at:

<https://www.cdc.gov/coronavirus/2019-ncov/travelers/ from-other-countries.html >.

[3] Statista. COVID-19 Impact on Flight Frequency of Global Airlines 2020 | Statista. 2020. [online] Available at:

<https://www.statista.com/statistics/1104036/novel-cor onavirus-weekly-flights-change-airlines-region/>.

[4] V. Hottenroth. The Impact Of COVID-19 On E-Commerce By Category [Updated Monthly] Bazaarvoice. 2020. [online] Bazaarvoice. Available at: <https://www.bazaarvoice.com/blog/the-impact-of-covi d-19-on-e-commerce-by-category-updated-weekly/> .

[5] K. Kulach, K.. Coronavirus Ecommerce Checklist: A Must-Have for Ebay \& Amazon Sellers. 2020. [online] Webinterpret. Available at: $<$ https://www.webinterpret.com/us/blog/coronavirus-ec ommerce-checklist-ebay-amazon/>.

[6] N. Manepalli, and S. Nagvenkar. Food Industry Feeling the Impact Of COVID-19. 2020. [online] Vitafoods Insights. Available at: $<$ https://www.vitafoodsinsights.com/news/food-industr y-feeling-impact-covid-19>.

[7] A. Mathradas. The Double-Sided Impact Of COVID-19 On E-Commerce. 2020. [online] Total Retail. Available at: $<$ https://www.mytotalretail.com/article/the-double-side d-impact-of-covid-19-on-e-commerce/>.

[8] J. Mulfati. Coronavirus News: Regular Updates On COVID-19'S Impact on The Airline Industry. 2020. [online] APEX | Airline Passenger Experience. Available at: <https://apex.aero/coronavirus>.

[9] A. Palmer. How the Coronavirus and Retail Closures Are Accelerating the Rise of Amazon. 2020. [online] CNBC. Available at: <https://www.cnbc.com/2020/04/19/coronavirus-retailclosures-speed-the-rise-of-amazon.html>.

[10] Nytimes.com. See How All 50 States Are 
Reopening (And Closing Again). 2020. [online]. Available at:

<https://www.nytimes.com/interactive/2020/us/states-re open-map-coronavirus.html>. 